\title{
Research on Design Schemes of 500kV Convertor Station Grounding
}

\section{Grid}

\author{
CHEN Wei ${ }^{1, a}$, SUN Yong ${ }^{1, b}$, CHEN Zihan ${ }^{2, c}$, WANG Tong ${ }^{2, d}$, FAN Youping ${ }^{2, e}$ \\ ${ }^{1}$ EHV Power Transmission Company Maintenance\&Test Center, CSG, Guangzhou, China \\ ${ }^{2}$ School of Electrical Engineering, Wuhan University, Wuhan, China \\ a47107843@qq.com, ${ }^{\mathrm{b}}$ sunyong@ehv.csg.cn, ${ }^{\mathrm{c} 827625357 @ q q . c o m},{ }^{\mathrm{d}}$ wangtongedu@163.com, \\ 'ypfan@whu.edu.cn
}

Keywords:convertor station; design; grounding grid; grounding resistance; Soil resistivity Abstract.With the development of HVDC, transmission capacity and transmission voltage level are both increasing. Under this situation, designing reliable grounding grid is more demanding. For areas with high soil resistivity, the grounding parameters can hardly meet relevant requirements. To solve this problem, this paper takes Luxi convertor station as an example to illustrate the designing process, and analyzes different design schemes. The results show that for areas with high deep soil resistivity the effect of using vertical grounding rods is slight, while the one of lengthening horizontal grounding objects is evident.

\section{Introduction}

For the Ultra-high voltage converter station which plays an important role in power system interconnection and transmits huge power over long distance, designing reliable grounding grid is more demanding because transmission capacity and transmission voltage level are both increasing ${ }^{[1]}$. Transmitting the earth fault current to the underground is the main role of the grounding grid which is to limit the step potential differences andcontact potential difference. At present, with the development of china market economy and HVDC, transmission capacity and transmission voltage level are both increasing ${ }^{[2]}$. Thus, the earth fault current will also increase. To maintain the electrical power system stable and safe, the permissible grounding grid resistance will be smaller and smaller. The high grounding grid resistance will lead to the high earth potential which will put workers and electrical equipment in danger. More than that,the counterattack of ground voltage will lead to destruction of insulation ${ }^{[3]}$.

Because of the lack of available arable land, most of converter stations are established in the high soil resistance area ${ }^{[4]}$.Meanwhile, there is less available land to establish converter stations. The grid grounding resistance of the convertor station usually cannot meet requirements. Under this circumstance, it is necessary to design compound grounding grids to solve this problem economically and effectively, according to the electric power environmentand soil environment. To maintain that the converter stations operate safely andreliable, it has important theoretical significance and practical value ${ }^{[5]}$.

\section{Design Requirements}

Grounding Grid Resistance Requirements. According to national standards, the grounding grid resistance requirements of converter station are as follows. 
(1) The Grounding Grid Resistance

$$
R \leq \frac{2000}{I_{G}}(1)
$$

$\mathrm{R} —$ the maximum grounding grid resistance considering seasonal variation $(\Omega)$.

$\mathrm{I}_{\mathrm{G}}$ - the maximum effective value of ground fault unsymmetrical current(A).

(2) When the grounding grid resistance can't meet the formula (1), the limits could be relaxed considering economic factors and technical factors. Following the relevant state regulations, the ground voltage limits could increase to $5 \mathrm{kV}$. If necessary, the limits could be relaxed more by the calculation and analysis. And it could not put workers and electrical equipment in danger.

GB 50150-2006 regulates thatwhen I $>4000 \mathrm{~A}, \mathrm{Z} \leq 0.5 \Omega$.

This paper designs the grounding grid which meets the requirements that grounding grid resistance is under $0.5 \Omega$ and the groundvoltage is under $5 \mathrm{kV}$.

Step Potential Differences and Contact Potential Difference Requirements. DL/T 621-1997 regulates that step potential differences and contact potential difference of converter station should meet the requirements as follows.

For $110 \mathrm{kV}$ and above grounding grid, when it occurs single-phase ground short circuit or two-phase ground fault, step potential differences and contact potential difference of converter station should be as follows.

$$
\begin{aligned}
& U_{t}=\frac{174+0.17 \rho_{f}}{\sqrt{t}} \\
& U_{s}=\frac{174+0.7 \rho_{f}}{\sqrt{t}}
\end{aligned}
$$

$U_{t} \longrightarrow$ contact potential difference, $\mathrm{V}$

$U_{s} \longrightarrow$ step potential differences, $\mathrm{V}$

$\rho_{f}$ earth resistivity, $\Omega \cdot m$

$\mathrm{t} \_$duration of fault short-circuit current, $\mathrm{s}$

\section{Main Methods of Resistance Reducing}

Vertical grounding rods.According to DL/T621-1997, when soil resistivity of deep layer soil is low, grounding grid resistance could be reduced by setting up vertical grounding rods. Especially to high soil resistivity area which is inappropriate to set up grounding device byregular methods, vertical grounding rods is an effective way to reduce the grounding grid resistance.

Extensional horizontal grounding objects. The area ofgrounding grid and soil resistivity is the key to grounding grid resistance. The most effective way to reduce grounding grid resistance is expanding the grounding grid area. Expanding the grounding grid area is the fundamental principle of extensional horizontal grounding objects. High land-use fees are not necessary to this way. But it is subject to land area, amplifying grounding objects is commonly used to expanding thegrounding grid area.

Filling ground resistance reducing material.According to DL/T621-1997, in the high soil resistivity area, soil around grounding electrode could be replaced by ground resistance reducing 
material to reduce the grounding grid resistance. Normally, filling ground resistance reducing material is supplementary method in coordination with vertical grounding rods and extensional horizontal grounding objects.

\section{Maximum Grounding Fault Current}

According to power system topology, power system parameter, transformer parameter, line parameter of Luxi back to back converter station, we establish short-circuit currentcalculation model and calculate the maximum grounding fault current under different current divider coefficient for the maximum rounding grid resistance limit.

According to power system parameter, we set up different short-circuit points to calculate fault current by ATP. Such as rectifier side inconverter station, the first tower on the rectifier side, the second tower on the rectifier side, inverter side in converter station, the first tower on the inverter side, the second tower on the rectifier side.

The result shows that short-circuit current are highest whensingle-phase short circuit occurs on the rectifier side in converter station. For the high grounding fault current in Luxi converter station and high soilresistivity can't meet the grounding grid resistance requirements. In this section, aerial earth wire to current divider is given.

Reducing the grounding grid resistance of the second tower from $50 \Omega$ to $20 \Omega$, ground potential is under $5 \mathrm{kV}$. The result is as follow in Table 1.

Tab1.Short-circuit current(ground potential under 5kV)

\begin{tabular}{ccc}
\hline No. & Type & Value \\
\hline 1 & short-circuit current $(\mathrm{kA})$ & 29.19 \\
2 & earth-fault current $(\mathrm{kA})$ & 4.27 \\
3 & neutral point of transformer branch current on rectifier side $(\mathrm{kA})$ & 6.38 \\
4 & aerial earth wire branch current on rectifier side $(\mathrm{kA})$ & 13.72 \\
5 & neutral point of transformer branch current on inverter side $(\mathrm{kA})$ & 0.06 \\
6 & aerial earth wire branch current on inverter side $(\mathrm{kA})$ & 5.55 \\
7 & branch current $(\mathrm{kA})$ & 24.93 \\
8 & shunt factor & 0.15 \\
9 & grounding grid resistance $(\Omega)$ & 1.00 \\
\hline
\end{tabular}

Reducing the grounding grid resistance of the second tower from to $10 \Omega$, grounding grid resistance is $0.5 \Omega$. The result is as follow in Table 2 .

Tab 2.Short-circuit current

\begin{tabular}{ccc}
\hline No. & Type & Value \\
\hline 1 & short-circuit current $(\mathrm{kA})$ & 29.19 \\
2 & earth-fault current $(\mathrm{kA})$ & 6.90 \\
3 & neutral point of transformer branch current on rectifier side $(\mathrm{kA})$ & 6.38 \\
4 & aerial earth wire branch current on rectifier side $(\mathrm{kA})$ & 12.30 \\
5 & neutral point of transformer branch current on inverter side $(\mathrm{kA})$ & 0.04 \\
6 & aerial earth wire branch current on inverter side $(\mathrm{kA})$ & 4.48 \\
7 & branch current $(\mathrm{kA})$ & 22.33 \\
8 & shunt factor & 0.24 \\
9 & Maximum earth-fault current $(\mathrm{kA}) D_{f}=1.1669$ & 8.07 \\
\hline
\end{tabular}




\section{Equivalent Soil Resistivity}

Theequivalent soil resistivity plays an important role in determining the grounding grid parameters. According to measurement results of soil resistivity, equivalent method of soil resistivity is given in this section based on CDEGS in Table 3.

Tab3.Soil resistivity equivalent result

\begin{tabular}{ccc}
\hline Layer & Soil Resistivity $(\Omega \mathrm{m})$ & Depth $(\mathrm{m})$ \\
\hline 1 & 144.9184 & 1.992869 \\
2 & 565.4620 & 15.44711 \\
3 & 1215.847 & infinity \\
\hline
\end{tabular}

Thus, it is concluded that the surface layersoil resistivity in Luxi converter station is about $144.9184 \Omega \mathrm{m}$. According to (2) and (3), the contact potential difference limit is $334 \mathrm{~V}$, and the step potential difference is $464 \mathrm{~V}$.

\section{Grounding Grid Design}

Preliminary Design. According to the floor plans of Luxi converter station, preliminary grounding grid design is given. In the station, the material of grounding objects is $80 \times 8$ galvanized flat steel. Flat bar spacing is $4 \sim 15 \mathrm{~m}$. Burial depthis $0.8 \mathrm{~m}$. In GIS, the diameter of horizontal grounding objects is $11.484 \mathrm{~mm}$, the material of grounding objects is $4 / 0$ solid copper, solid copper spacing is 4.5 10m.

Horizontal grounding objects spacing,

(1) Spacing of edge and corner are smaller than spacing of inside.

(2) Grounding objects spacing is small around GIS.

(3) Grounding objects only established around the building.

There are different ways to reduce the grounding grid resistancein Table 4.

Tab4.Different ways to reduce the grounding grid resistance

\begin{tabular}{|c|c|c|c|}
\hline No & Method & Resistance $/ \Omega$ & Effect analysis \\
\hline 1 & l & 1.086928 & $\begin{array}{l}\text { Compare to base } \\
\text { value }\end{array}$ \\
\hline 2 & $\begin{array}{l}\text { Resistance-reducing agent }(0.15 \mathrm{~m} \text { thick, } 1 \Omega \mathrm{m}) \text { are added to all } \\
\text { the grounding objects. }\end{array}$ & 1.082740 & $0.385 \%$ \\
\hline 3 & $\begin{array}{l}\text { Resistance-reducing agent }(0.15 \mathrm{~m} \text { thick, } 1 \Omega \mathrm{m}) \text { are added tothe } \\
\text { grounding objects around the grounding grid. }\end{array}$ & 1.083964 & $0.273 \%$ \\
\hline 4 & $\begin{array}{l}\text { All grounding objects are copper and diameter is } 11.484 \mathrm{~mm} \text {,no } \\
\text { resistance-reducing agent. }\end{array}$ & 1.078490 & $0.776 \%$ \\
\hline 5 & $\begin{array}{l}\text { All grounding objects are copper and diameter is } 11.484 \mathrm{~mm} \text {, } \\
\text { resistance-reducing agent }(0.15 \mathrm{~m} \text { thick, } 1 \Omega \mathrm{m}) \text { are added to } \\
\text { grounding objects around the grounding grid. }\end{array}$ & 1.073504 & $1.24 \%$ \\
\hline 6 & $\begin{array}{l}\text { All grounding objects are copper and diameter is } 11.484 \mathrm{~mm} \text {, } \\
\text { resistance-reducing agent }(0.15 \mathrm{~m} \text { thick, } 1 \Omega \mathrm{m}) \text { are added to } \\
\text { grounding objects. }\end{array}$ & 1.071549 & $1.41 \%$ \\
\hline
\end{tabular}

Vertical Grounding Rods Design. The design of add 178 vertical grounding rods

(1)All grounding objects are copper and diameter is $11.484 \mathrm{~mm}$. 
(2) 178 vertical grounding rods (copper length is $100 \mathrm{~m}$ and diameter is $11.484 \mathrm{~mm}$ ) are added to cross point and corner of grounding objects around the grounding grid.

(3)Resistance-reducing agent $(0.15 \mathrm{~m}$ thick, $1 \Omega \mathrm{m})$ are added to all grounding objects and vertical grounding rods.

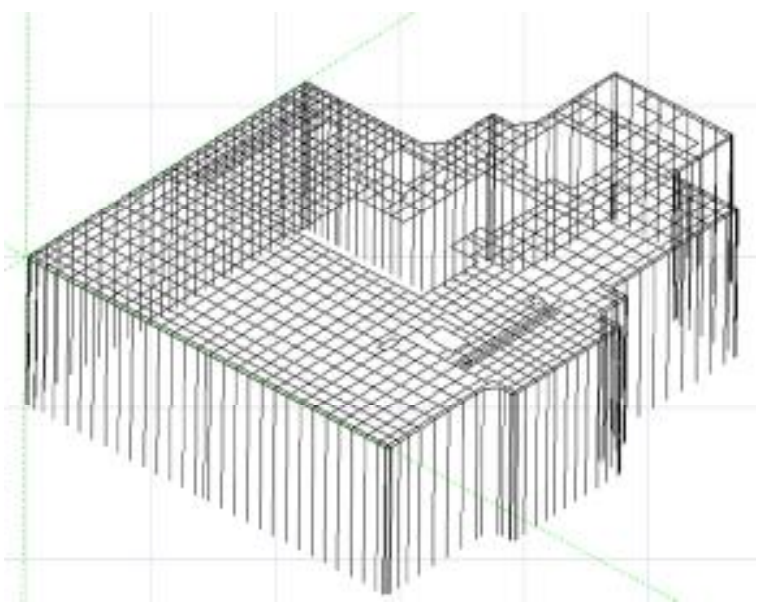

Fig 1.Vertical grounding rods design

The grounding grid resistance is $0.8830424 \Omega$ by this designin Figure 1 . It can be seen that because of the high soil resistivity, vertical grounding rods design can't meet the requirement that grounding grid resistance should be under $0.19 \Omega$ or $0.5 \Omega$.

Extensional horizontal grounding objects design.The design of adding 8 extensional horizontal grounding objects(length is $700 \mathrm{~m}$ ) in Figure 2.

(1) The grounding gridin station has no change.

(2) 8 extensional horizontal grounding objects(length is $700 \mathrm{~m}$ ) distribute as hub-and-spoke.

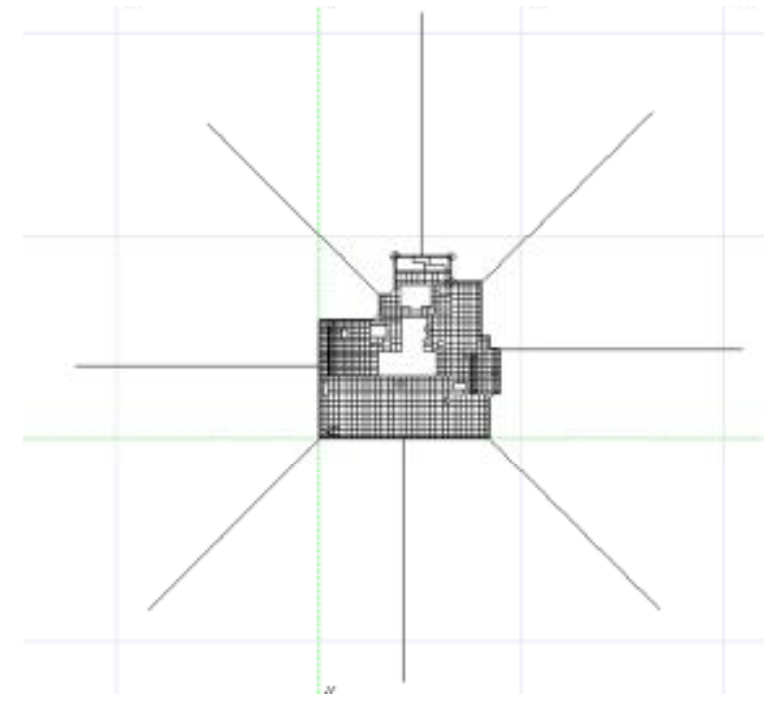

Fig 2.Extensional horizontal grounding objects(length is $700 \mathrm{~m}$ ) 
Tab 5 Different resistance reduction plans of radial 700-meter-long extension arrangement

No. Methods

(1) Grounding objects in GIS area are copper and the diameter is $11.484 \mathrm{~mm}$;

(2) Grounding subjects in other area are80x8galvanized flat steel;

(3) 700-meter-long extensive horizontal electrodes are 80x8galvanized flat steel;

(4) No resistance reduction agent is added to the grounding objects.

(1) Grounding objects in GIS area are copper and the diameter is $11.484 \mathrm{~mm}$;

(2) Grounding subjects in other area are80x8galvanized flat steel;

2 (3) 700-meter-long extensive horizontal electrodes are 80x8galvanized flat steel;

(4) Resistance-reducing agent $(0.15 \mathrm{~m}$ thick, $1 \Omega \mathrm{m})$ are added to grounding objects around the grounding grid and extensive electrodes.

(1) Grounding objects in GIS area are copper and the diameter is $11.484 \mathrm{~mm}$;

(2) Grounding subjects in other area are 80x8galvanized flat steel;

(3) 700-meter-long extensive horizontal electrodes are flexible graphite;

(4) No resistance reduction agent is added to the grounding objects.

(1) Grounding objects in GIS area are copper and the diameter is $11.484 \mathrm{~mm}$;

(2) Grounding subjects in other area are 80x8galvanized flat steel;

4 (3) 700-meter-long extensive horizontal electrodes are flexible graphite;

(4) Resistance-reducing agent $(0.15 \mathrm{~m}$ thick, $1 \Omega \mathrm{m})$ are added to grounding objects around the grounding grid and extensive electrodes.

Tab6.Grounding resistance of different plans

\begin{tabular}{ccc}
\hline No. & Grounding resistance $(\Omega)$ & Effect analysis \\
\hline 1 & 0.4952850 & control \\
2 & 0.4892988 & $-1.208 \%$ \\
3 & 0.4961835 & $+0.18 \%$ \\
4 & 0.4881788 & $-1.43 \%$ \\
\hline
\end{tabular}

It can be seen that when the extensional horizontal grounding object is 700 meters in table 5 and 6 , all design can meet the requirement that the grounding grid resistance is under $0.5 \Omega$. Adding resistance-reducing agent,Flexible graphite base grounding objects is better than $80 x 8$ galvanized flat steel.

The design of adding 8 extensional horizontal grounding objects(length is $150 \mathrm{~m}$ ) in Figure 3.

(1) The grounding grid in station has no change.

(2) 8 extensional horizontal grounding objects (length is $150 \mathrm{~m}$, depth is $2 \mathrm{~m}$ ) distribute as hub-and-spoke. 


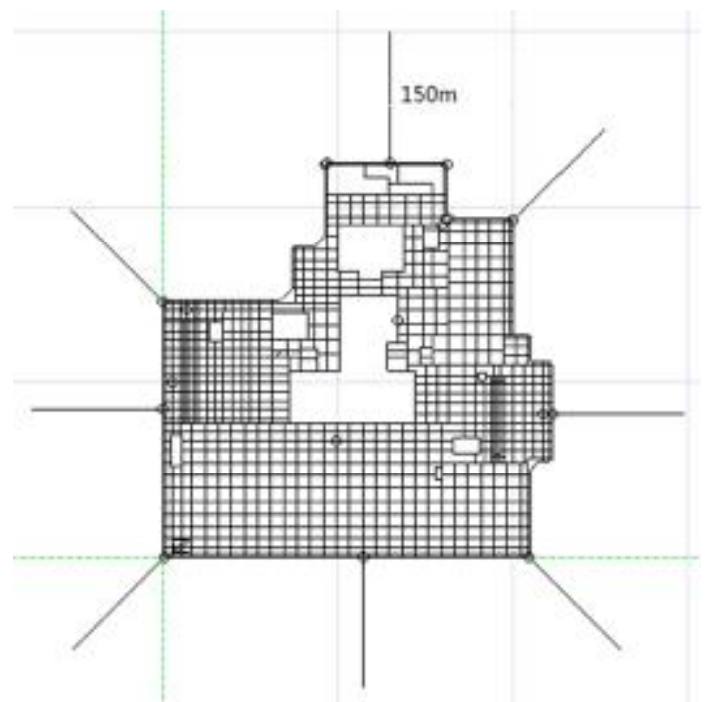

Fig 3.Extensional horizontal grounding objects(length is $150 \mathrm{~m}$, depth is $2 \mathrm{~m}$ )

Tab 7.Different resistance reduction plans of radial 150-meter-long extension arrangement

\begin{tabular}{l} 
No. \\
\hline (1) Grounding objects in GIS area are copper and the diameter is $11.484 \mathrm{~mm} ;$ \\
(2) Grounding subjects in other area are $80 x 8$ galvanized flat steel; \\
(3) 150 -meter-long extensive horizontal electrodes are $80 x 8$ galvanized flat steel; \\
(4) Resistance-reducing agent $(2.2 \mathrm{~cm}$ thick, $1 \Omega \mathrm{m})$ are added to extensive electrodes. \\
(1) Grounding objects in GIS area are copper and the diameter is $11.484 \mathrm{~mm} ;$ \\
(2) Grounding subjects in other area are $80 x 8$ galvanized flat steel; \\
(3) 150 -meter-long extensive horizontal electrodes are flexible graphite; \\
(4) Resistance-reducing agent (3.6cm thick, $1 \Omega \mathrm{m})$ are added to extensive electrodes.
\end{tabular}

Tab 8. Grounding resistance of different resistance reduction plans

\begin{tabular}{ccc}
\hline No. & Grounding resistance $(\Omega)$ & Excess \\
\hline 1 & 0.8998415 & $10.015 \%$ \\
2 & 0.9 & $10 \%$ \\
\hline
\end{tabular}

It can be seen that extensional horizontal grounding objects design is better than vertical grounding rods design in Table 7 and 8 . The grounding grid resistance could be reduced to under $0.5 \Omega$.

\section{Conclusion}

This article researches on the designing plan of the grounding grid for $500 \mathrm{kV}$ convector station and taking Luxi convector station as an example to design the grounding grid and compare the resistance diminishing effects of different plans. The result shows that, if take the decreasing of grounding resistance to $0.5 \Omega$ as a limitation, according to most ground resistance designing principle, the plan which extends 8700 -meter-long earth electrodes meets the requirements. If the grounding voltage is extended to $5 \mathrm{kV}$, both the addition of vertical grounding resistance and the extension of horizontal electrodes could achieve the goal. For areas with high solid resistivity, such as Luxi convector station, the effect of vertical grounding resistance is indistinctive, to solve this problem, the extension of horizontal earth electrodes could be applied at the same time. 


\section{References}

[1] Kirschen D S,Wollenberg B F. Intelligent Alarm Processing in Power Systems[J]. Proceedings of the IEEE,1992,80(5):663-672.

[2]LIU Qingsong, XIA Daozhi. Expert System of Power System Fault Diagnosis Based on Forward and Backward Reasoning[J]. Power System Technology, 1999, 23(9): 66-68, 71.

[3] WU Xin, GUO Chuangxin. Power System Fault Diagnosis Approach Based on Bayesian Network[J]. Proceedings of the CSU-EPSA, 2005, 17(4): 11-15, 40.

[4]KUANG Yingchun, SHEN Yue, LUO Richeng. Fault Diagnosis of Power System Based on the UnionDecomposition Technology of Petri Net[J]. Proceedings of the CSU-EPSA, 2008, 20(1): 57-60.

[5] WEN Fuquan, HAN Zhenxiang. A NEW APPROACH TO ALARM PROCESSING IN POWER SYSTEMSBASED UPON THE SET COVERING THEORY AND TABU SEARCH METHOD[J]. Automation of Electric Power Systems, 1997, 21(2): 18-23, 36. 